\title{
Prediction of the Likelihood of Interference at Frequencies of 30 to 42 Megacycles in Alaska
}

\author{
T. N. Gautier, Jr., and C. J. Sargent
}

\begin{abstract}
The likelihood of interference with very-high-frequency networks in Alaska from stations operating on similar frequencies in other parts of the world, as a function of season, sunspot number, and time of day, is presented. This example serves as a model for similar computations for other communication links. Calculations are based upon regular reflection from the $F 2$ laver, and data are supplied for estimating the probability of interference from sporadic- $E$ reflections.
\end{abstract}

\section{Introduction}

At the request of the Civil Aeronautics Administration a study was made of the likelihood of interference with the operation of a proposed very-high-frequency line-of-sight network in Alaska caused by ionospheric propagation of signals between stations within the network and of signals from distant stations outside the network. The study was made for operating frequencies of 30,36 , and $42 \mathrm{Mc}$. The likelihood of interference at these frequencies is inferred from the likelihood of occurrence of maximum usable frequencies (MUF) equal to or greater than these frequencies calculated for propagation paths between stations within the network and between distant points and two representative points in the network.

This specific study is an example of a communication problem of general interest, and is presented in full to serve as a guide in solving similar problems.

Nome, Alaska, and Annette Island, Alaska, near the extremes of the network, were chosen as the points within the network for the study of interference from distant stations.

The likelihood of the MUF exceeding 30, 36, and $42 \mathrm{Mc}$ was calculated for three classes of propagation paths: (1) $F$-layer paths from stations at distances greater than $4,600 \mathrm{~km}$ from Nome and Annette Island, respectively. (2) F2-layer paths less than $4,000 \mathrm{~km}$ in length, including paths between network stations. (3) Sporadic- $E$ paths between stations of the network.

\section{Basic F2-4000 MUF Prediction Charts}

Using standard procedures, F2-4000 MUF contour charts similar to those appearing in the CRPL-D series [1] ${ }^{1}$ were drawn for latitudes $30^{\circ}$ to $70^{\circ}$ north in the I-zone, for sunspot numbers $60,80,100,120$, and 140, and the months June and December. It was not necessary to prepare charts for sunspot numbers less than 60 for the problem under consideration.

Sunspot numbers referred to are 12-month averages of relative sunspot numbers. The average maximum 12-month average sunspot number for the past 10 cycles is 105 , with a standard deviation of 24 . The maximum for the present cycle, which occurred in 1947 , was 152 .

\footnotetext{
1 Figures in brackets indicate the literature references at the end of this paper.
}

\section{Interference from Distant Stations}

Using the charts referred to in section 2, figures 1 to 34 were prepared. Figures 1 to 16 are for reception at Nome, whereas figures 17 to 34 are for reception at Annette Island.

Curves on these charts show the predicted variation with sunspot number and time of day of the percentage of occurrence of conditions for reception at 30,36 , and $42 \mathrm{Mc}$ by $F 2$-layer propagation from transmitting stations located at distances of 4,000 $\mathrm{km}$ and over, in selected azimuth ranges measured clockwise from north at the receiving station. The azimuth ranges for paths terminating at Nome are $53^{\circ}$ to $117^{\circ}, 172^{\circ}$ to $254^{\circ}$, and $254^{\circ}$ to $299^{\circ}$. The azimuth ranges for paths terminating at Annette Island are $67^{\circ}$ to $157^{\circ}, 218^{\circ}$ to $277^{\circ}$, and $277^{\circ}$ to $322^{\circ}$. The world areas included in these azimuth ranges are shown in figures 35 and 36 . Charts for summer and winter conditions are presented. Charts on which the predicted occurrence is less than 10 percent for sunspot number 140 are omitted. Equinox conditions are approximately intermediate between those for summer and winter.

As an example, in figure 1 the chart for Nome, 30 $\mathrm{Mc}$, June, and azimuth range $53^{\circ}$ to $117^{\circ}$, conditions for reception of $30 \mathrm{Mc}$ at $0500 \mathrm{GCT}$ on 90 percent of the days of the month on the average shouid occur for a sunspot number of 135 . For sunspot number 70 , reception should occur on only 10 percent of the days on the average at $0500 \mathrm{GC} T$, whereas for sunspot number 120 , reception on 10 percent or more of the days should occur between about 1830 and 0730 , with about 75 -percent occurrence at 0500 .

The charts were constructed as follows:

1. The $2,000-\mathrm{km}$ circle around each receiving station shown in figures 35 and 36 , and the selected azimuth intervals, were traced on transparent paper.

2. Daily intervals for reception on more than a specified percentage of days were found by placing these sheets on the predicted 4,000-MUF charts, and noting the earliest and latest times at which the appropriate MUF contour intersected the segment of the $2,000-\mathrm{km}$ circle included in the given azimuth range as the transparency was moved horizontally from left to right across the MUF chart.

For reception on 50 percent of the days, the appropriate contour is that for MUF equal to the given frequency. The dispersion of daily values of 
the MUF is such that contours for MUF equal to $1 /(1+0.15)$ and $1 /(1-0.15)$ times the given frequency correspond approximately to $10-$ and $90-$ percent reception, respectively, [2, sec. 6.6, i]. Assuming that the distribution of percentage of MUF is Gaussian, contours for MUF equal to $1 /(1+0.08)$ and $1 /(1-0.08)$ times the given frequency would then correspond to 25 - and 75 -percent reception, respectively.

3 . Contours in figures 1 to 34 were then plotted by interpolation between the end points of the intervals determined in step 2. Figure 17 (b) is discussed below.

Although the predictions are based upon an assumed ring of transmitting stations $4,000 \mathrm{~km}$ distant from the receiving station extending over the indicated azimuth range, stations at greater distances in the same azimuth range are also included, provided the MUF at the control point nearest the transmitting station is greater than the given frequency. This will be true, usually, for transmitting stations in the land areas included in the azimuth ranges, except those west of the receiving station during the early hours of the predicted daily reception period, and those east of the receiving station during late hours of the predicted daily reception period, at distances well over $4,000 \mathrm{~km}$.

Actually, portions of the $2,000-\mathrm{km}$ circles around the receiving stations lie outside the I-zone. However, errors introduced by using I-zone predictions for these segments are believed to be less than other uncertainties in the predictions. The error in the position of portions of the curves on these charts may be of the order of 10 or 15 sunspot numbers.

It should be emphasized that these charts show the occurrence of conditions for interference from one or more of a number of distant stations operating on the same frequency and distributed over the entire azimuth range. The interference from a single station would be somewhat less than this. For example, the predicted interference at Annette Island from a station in Washington, D. C., operating at $30 \mathrm{Mc}$ in June is shown in figure 17 (b). This may be compared with figure 17 (a), which shows the predicted interference from stations throughout the azimuth range $67^{\circ}$ to $157^{\circ}$.

\section{Interference from Stations Within the Net- work and Other Stations at Distances Less Than 4,000 Km}

Figures 37 to 49 show the predicted occurrence of conditions for interference at 30,36 , and $42 \mathrm{Mc}$, via $F$-layer reflections from stations at distances less than $4,000 \mathrm{~km}$ as a function of distance and time of day for paths centered on $60^{\circ} \mathrm{N}$. latitude, the approximate latitude of the middle of the network. Charts are given for June and December and for sunspot numbers from 60 to 120 , in steps of 20 . They were prepared by using the MUF values at $60^{\circ} \mathrm{N}$. on the F2-4000 MUF charts and assuming a ratio of 4000 MUF to zero MUF equal to 2.9, and interpolating by means of the nomogram on page 85 of reference
[2]. Conditions for equinoctial months are intermediate between those for summer and winter. When the predicted occurrence was less than 10 percent at all times of the day for distances less than $4,000 \mathrm{~km}$, the chart was omitted.

It may be noted that the predicted occurrence for distances less than $2,000 \mathrm{~km}$, the maximum distance within the network, exceeds 10 percent only in winter near sunspot maximum.

Figure 50 shows the percentage of occurrence by seasons of vertical incidence sporadic- $E$ reflections $(f E s)$ at frequencies above $7 \mathrm{Mc}$, observed at Anchorage, Alaska, averaged over 4 years, May 1949 through April 1953. Occurrence of conditions for propagation of 30,35 and $40 \mathrm{Mc}$, based on the occurrence of $f E s$ above $7 \mathrm{Mc}$ may be estimated as follows:

The logarithm of the probability $P$ of occurrence of vertical incidence sporadic- $E$ reflections at frequencies higher than $f$ is roughly a linear function of the frequency [3]. Thus

or

$$
\log _{10} P=a+b f
$$

$$
\begin{aligned}
\log _{10}\left(P_{1} / P_{2}\right) & =b\left(f_{1}-f_{2}\right) \\
P_{1} / P_{2} & =10^{b\left(f_{1}-f_{2}\right)}=B^{\left(f_{1}-f_{2}\right)} .
\end{aligned}
$$

This does not apply if $P$ is close to 1.0 .

Analysis of Anchorage $f E s$ measurements indicates that the occurrence of $f E s$ above $5 \mathrm{Mc}$ is approximately $2 \frac{1}{2}$ times that for $f E s$ above $7 \mathrm{Mc}$. From the preceding relationship $B=(0.4)^{\frac{1}{2}}$, so that $P_{f}=$ $P_{7}(0.4)^{(f-7) / 2}$ and the probabilities of occurrence of vertical incidence $E s$ reflections above $6,8,9,10$, and $11 \mathrm{Mc}$ are $1.6,0.6,0.4,0.25$, and 0.16 , respectively, times the probability of occurrence above $7 \mathrm{Mc}$.

Assuming regular E-layer MUF factors, Es MUF equal to 30,35 , and $40 \mathrm{Mc}$, corresponds approximately to $f E s$ equal to 6,7 , and $8 \mathrm{Mc}$, respectively, for a distance of $2,000 \mathrm{~km}$, to $\mathrm{fEs}$ equal to 7,8 , and 9 $\mathrm{Mc}$, respectively, for a distance of $1,500 \mathrm{~km}$, and to fEs equal to 9,10 , and $11 \mathrm{Mc}$, respectively, for a distance of $1,000 \mathrm{~km}$.

The approximate relative frequencies of occurrence of $E s$ MUF greater than 30,35 , and $40 \mathrm{Mc}$, for distances of $1,000,1,500$, and $2,000 \mathrm{~km}$ (i. e., ratios to the occurrence of $\mathrm{fEs}$ above $7 \mathrm{Mc}$ ), based on the above relations, are summarized in table 1.

Referring again to figure 50, Anchorage $f E s$ above $7 \mathrm{Mc}$ shows little seasonal variation, which is in accord with observations at other stations in the auroral zone. Little is known about the sunspotcycle variation.

TABLE 1.

\begin{tabular}{|c|c|c|c|}
\hline \multirow{2}{*}{ Frequency } & \multicolumn{3}{|c|}{ Distance } \\
\cline { 2 - 4 } & $1,000 \mathrm{~km}$ & $1,500 \mathrm{~km}$ & $2,000 \mathrm{~km}$ \\
\hline & & & \\
\hline$M c$ & & 1.0 & 1.6 \\
30 & 0.4 & 0.6 & 1.0 \\
35 & .25 & .4 & 0.6 \\
40 & .16 & & \\
\hline
\end{tabular}


There is reason to doubt the exact quantitative significance of sporadic- $E$ measurements. They should, therefore, be regarded as indicating only roughly the occurrence of conditions for interference at network stations via sporadic- $E$ reflections.
[1] Basic radio propagation predictions, Ntl. Bur. Standards CRPL-D Series, U. S. Government Printing Office, Washington 25, D. C.

[2] Ionospheric radio propagation, NBS Cir. 462, U. S. Government Printing Office, Washington 25, D. C.

[3] M. Lindeman Phillips, Variations in sporadic- $E$ ionization observed at Washington, D. C., Trans. Am. Geophys. Union, 2871 (1947).
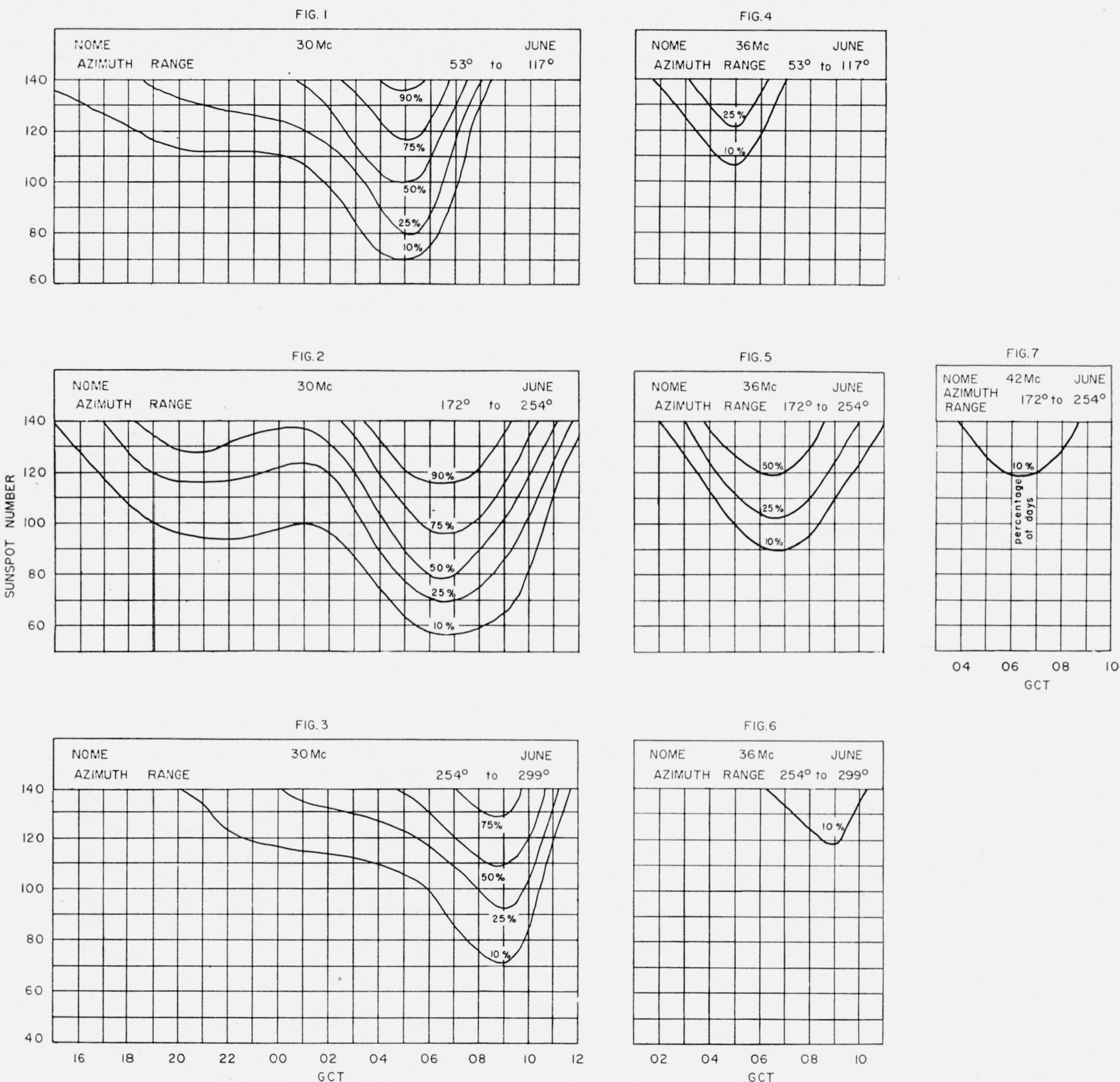

Figures 1 to 7 . Predicted occurrence of conditions for reception via F2-layer propagation. 

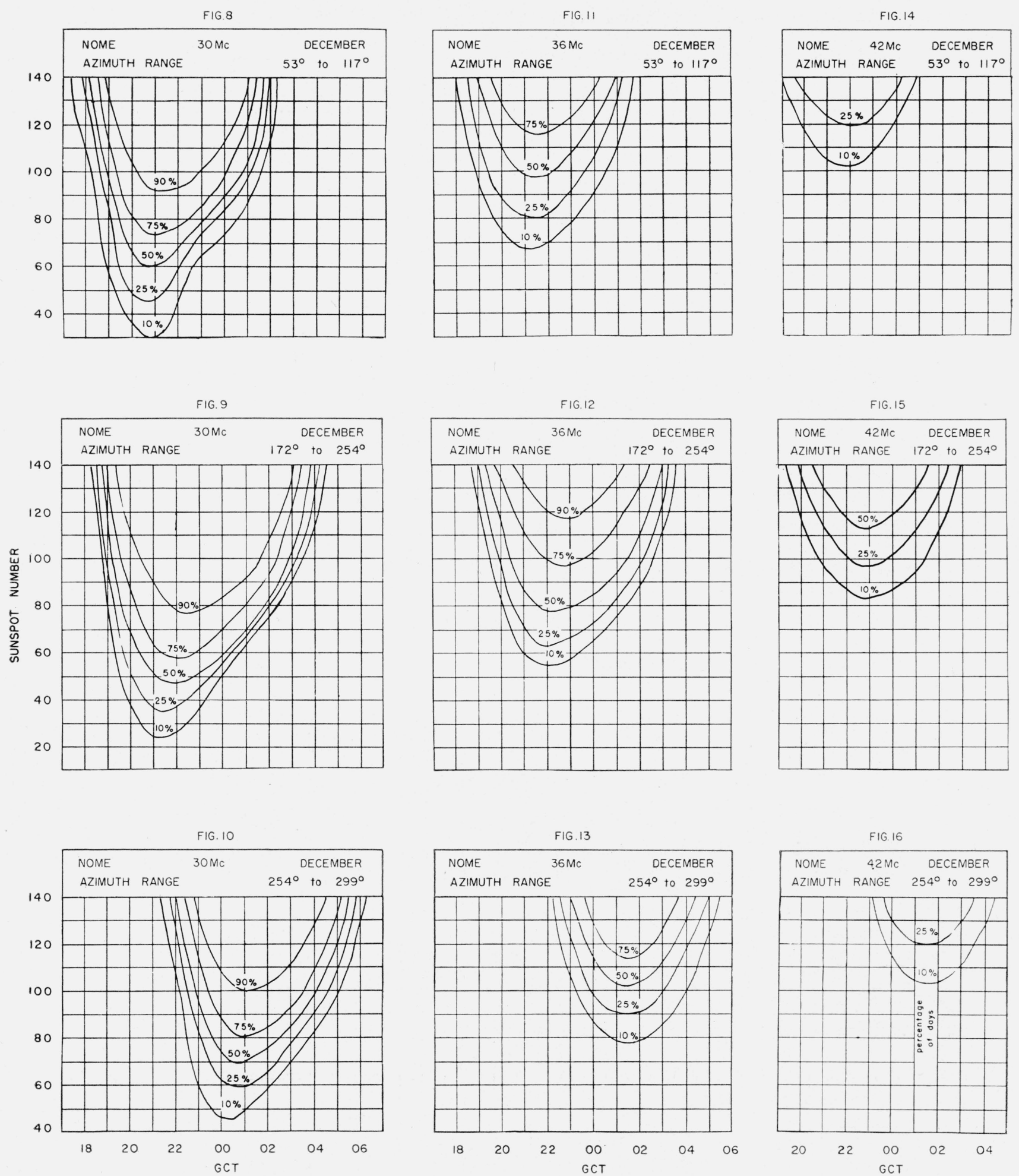

Figures 8 to 16. Predicted occurrence of conditions for reception via F2-layer propagation. 
FIG. 17 (a)

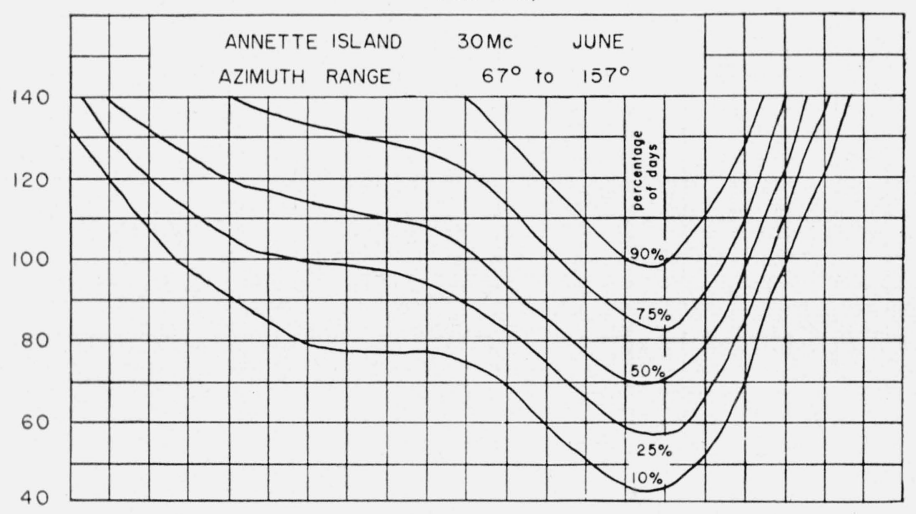

FIG. $17(b)$

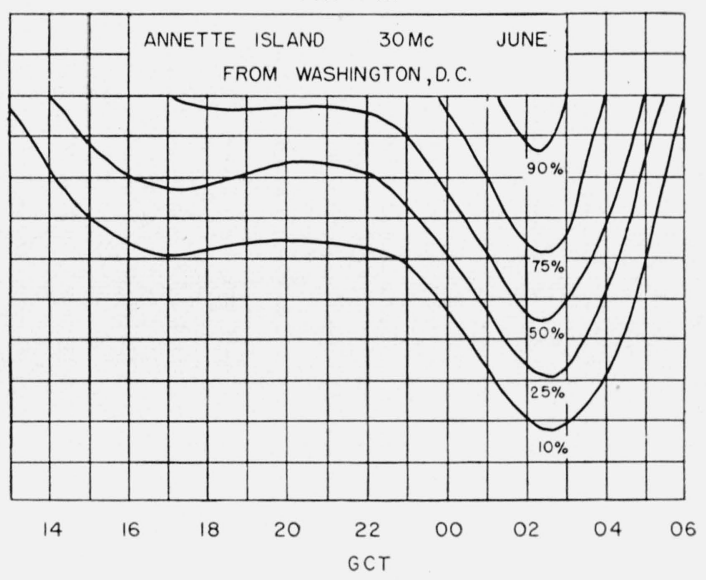

FIG. 18

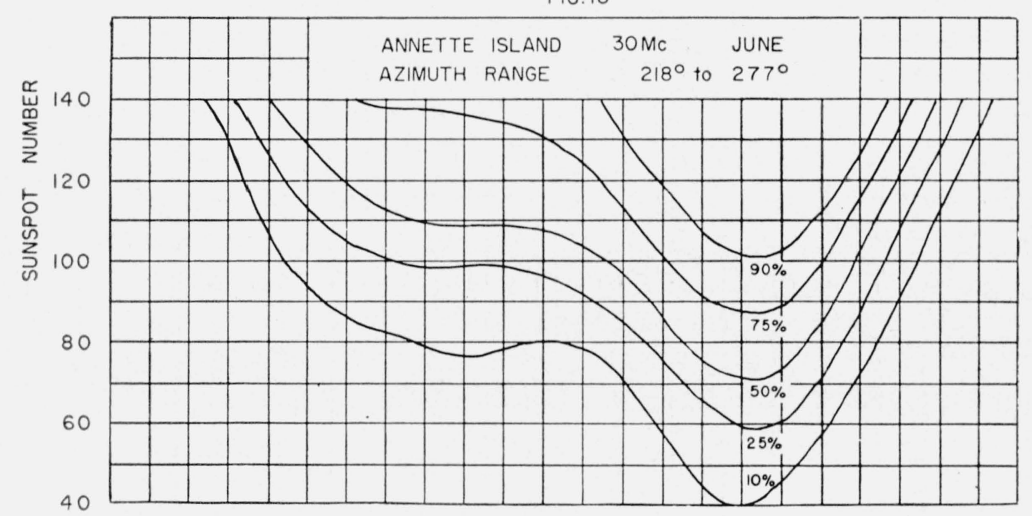

FIG. 19

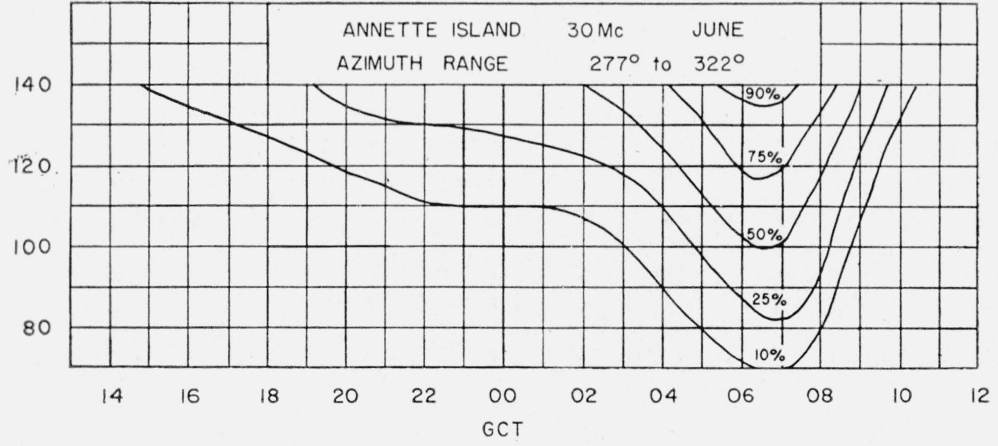

Figures 17 to 19. Predicted occurrence of conditions for reception via F2-layer propagation. 
FIG. 20

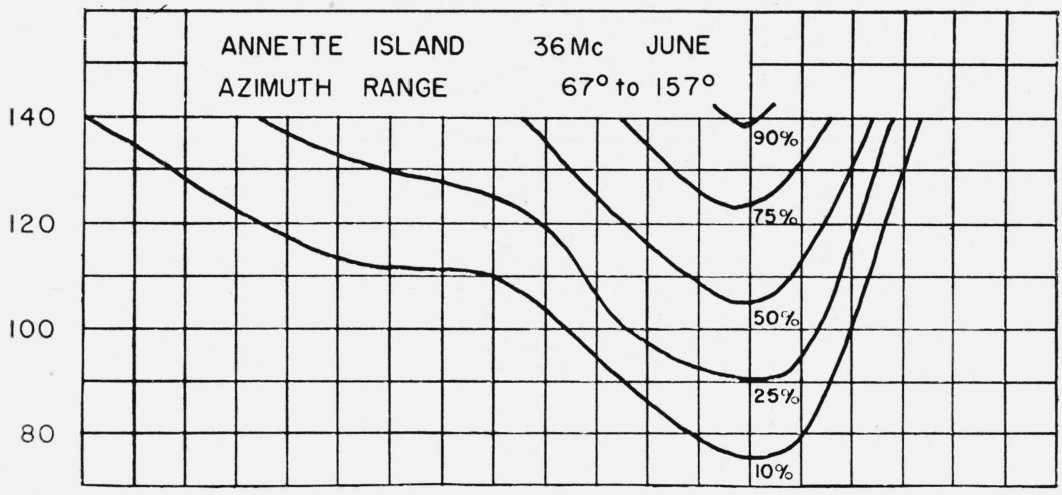

FIG. 2 I

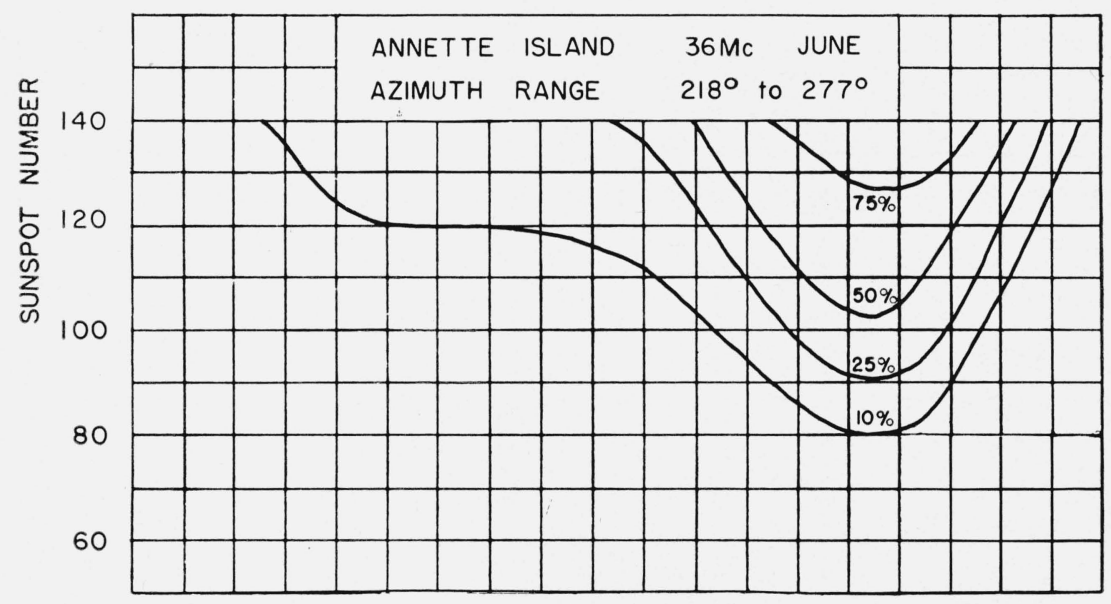

FIG. 22

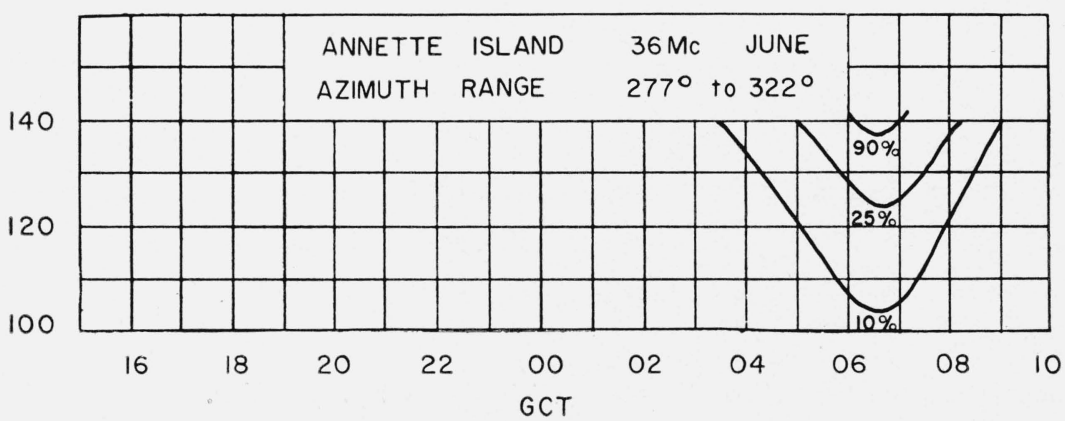

FIG. 23

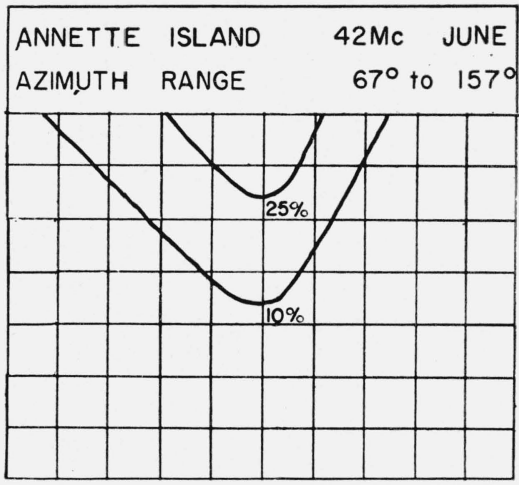

FIG. 24

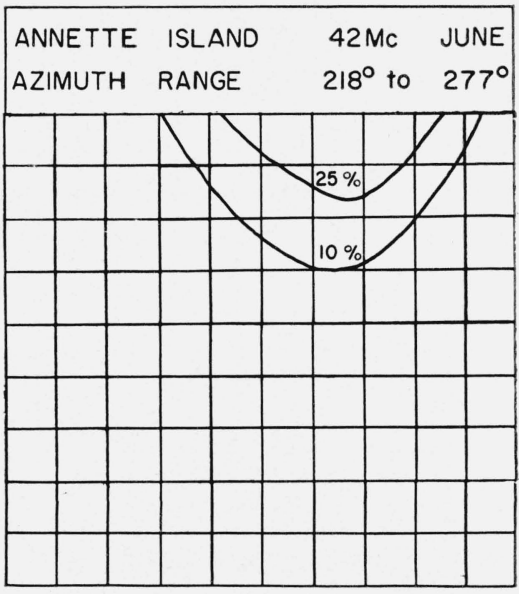

FIG. 25

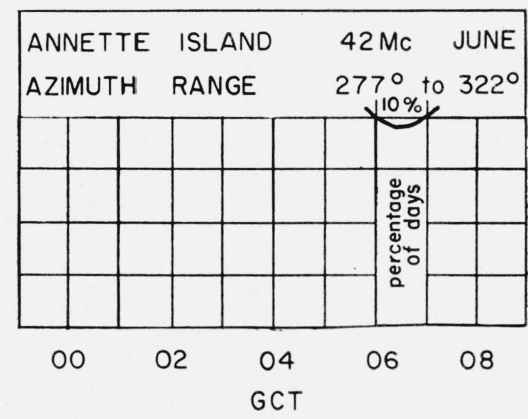

Figures 20 to 25. Predicted occurrence of conditions for reception via F2-layer propagation. 
FIG. 26

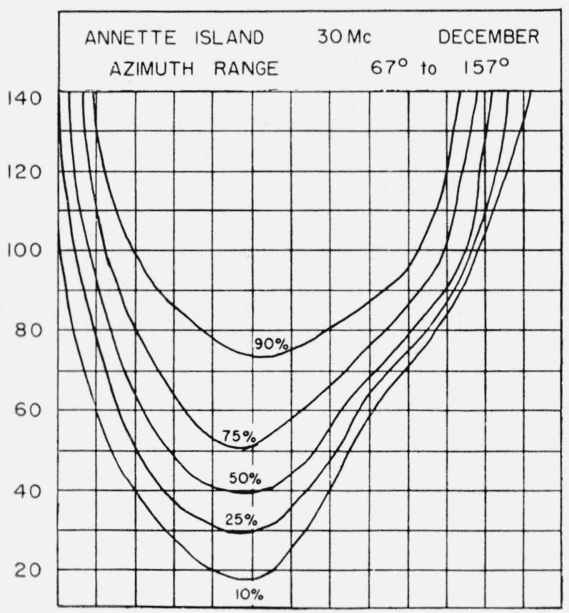

FIG. 29

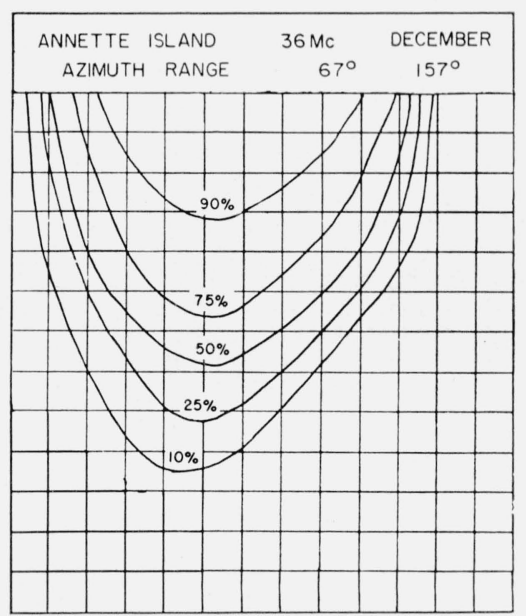

FIG. 32

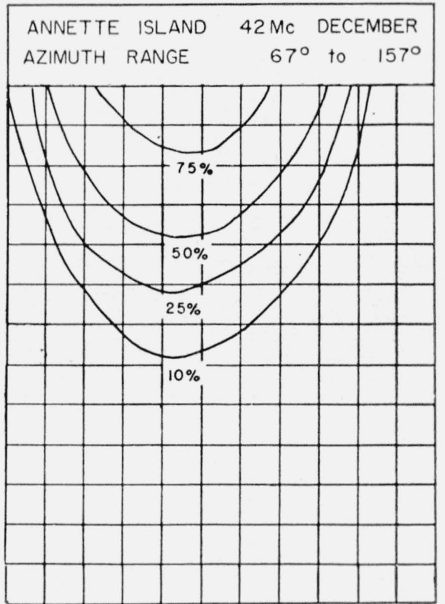

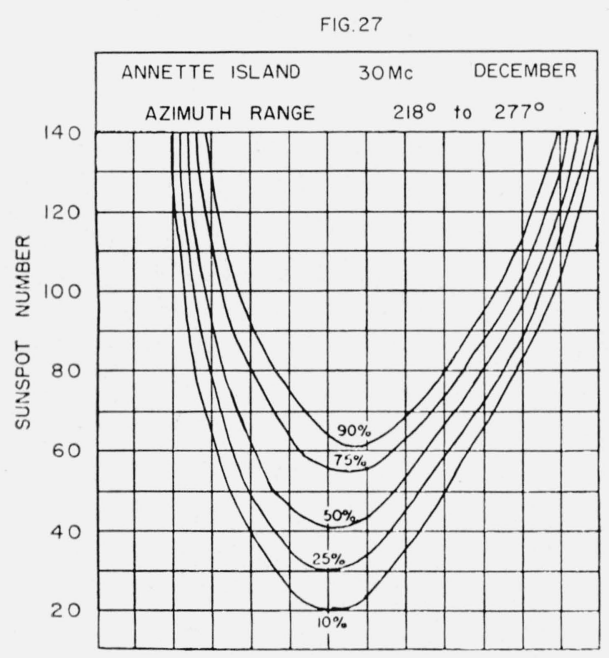
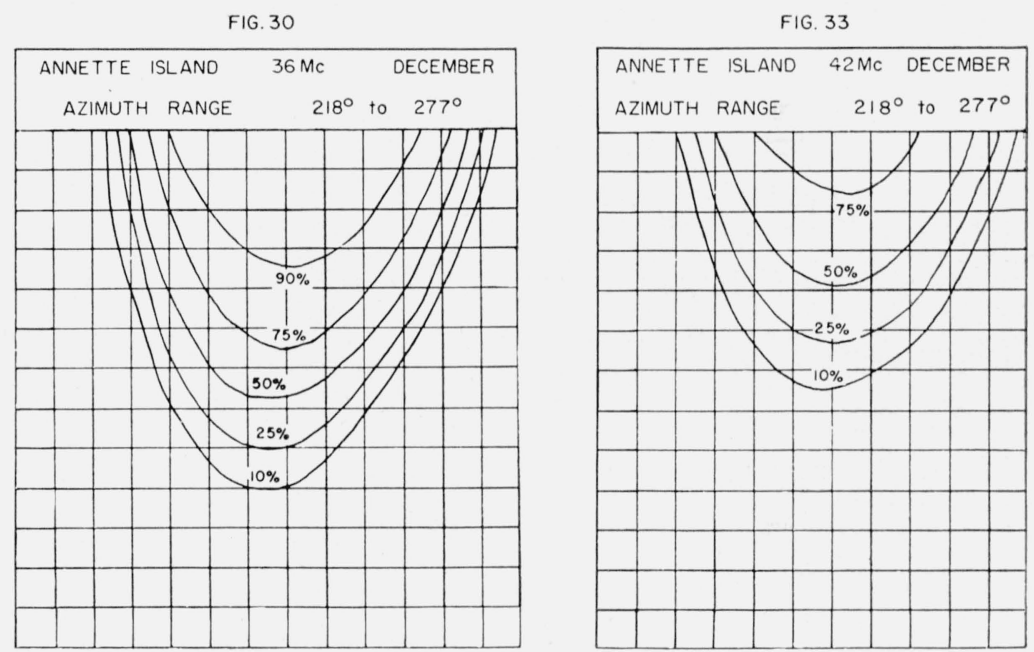

FIG. 28

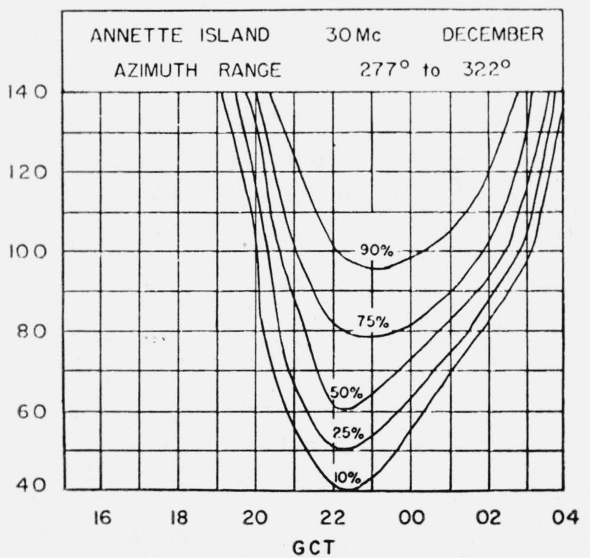

FIG 31

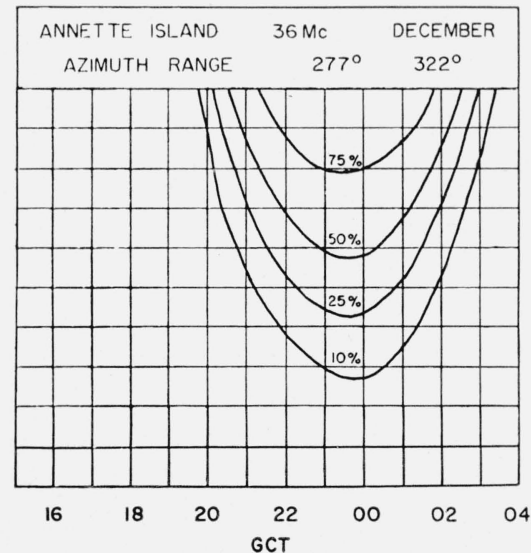

FIG. 34

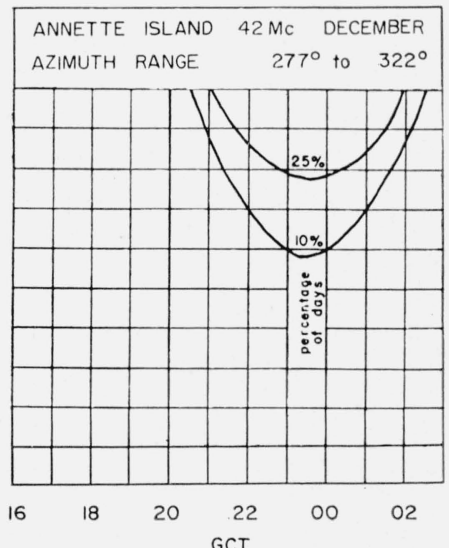

Figures 26 to 34. Predicted occurrence of conditions for reception via F2-layer propagation. 

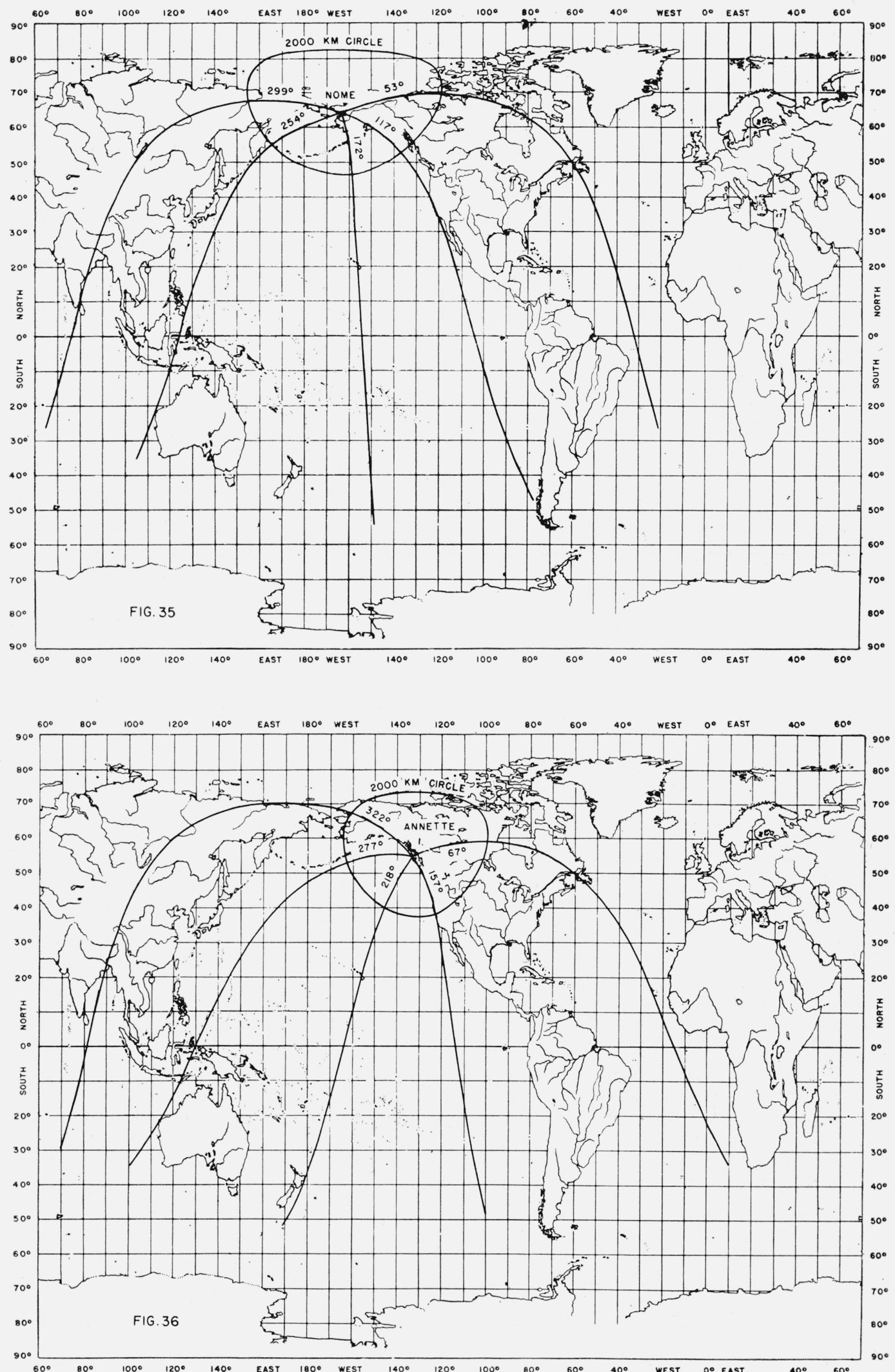

FIGUREs 35 and 36. Maps showing geographical areas included in selected azimuth sectors. 
FIG. 37

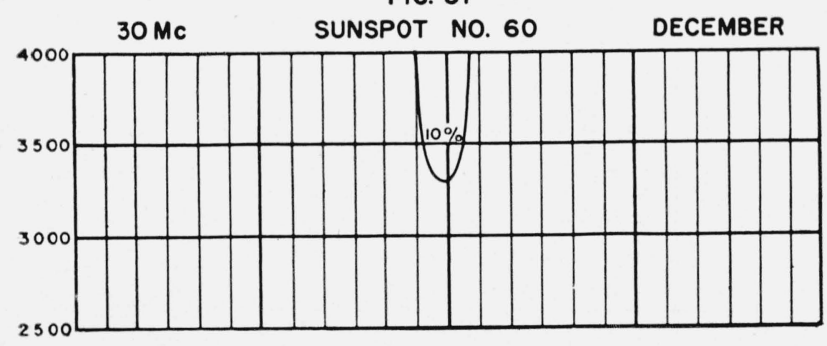

FIG. 38
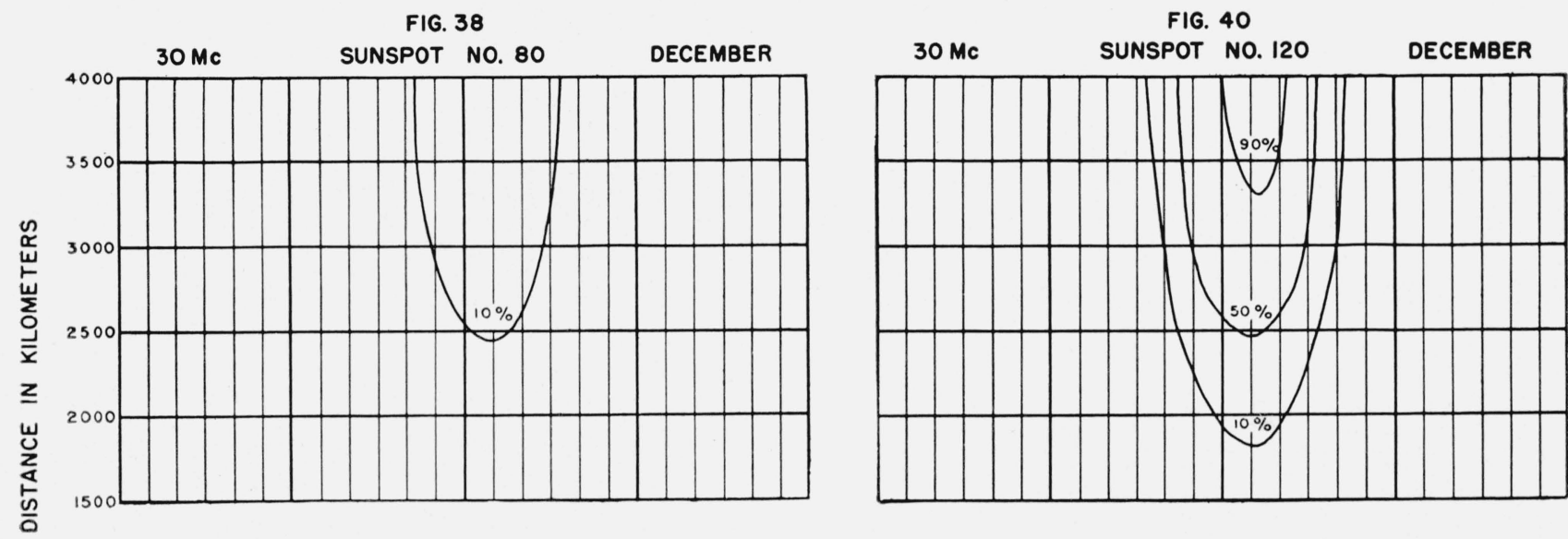

FIG. 39
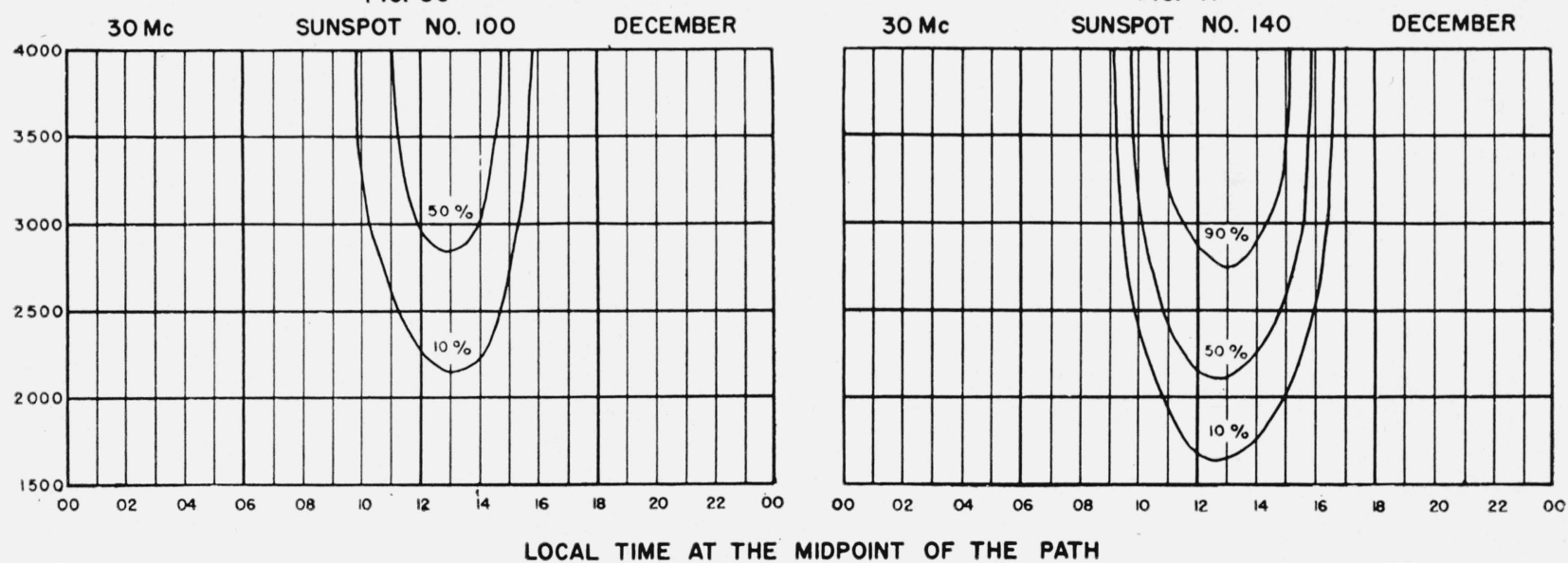

Figures 37 to 41. Predicted skip distance for F2-layer reflection at $60^{\circ} \mathrm{N}$. latitude, I-zone. 
FIG. 42

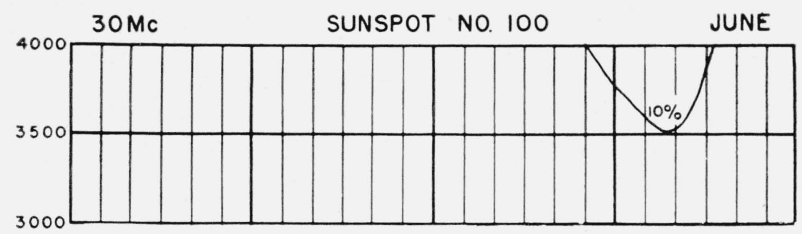

FIG. 43

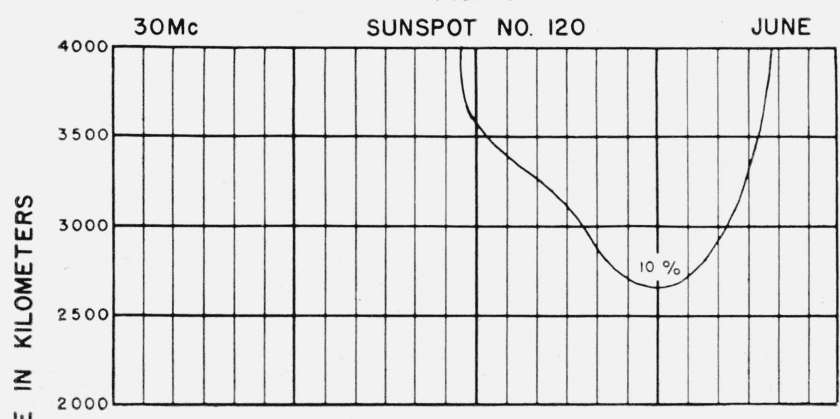

FIG. 44

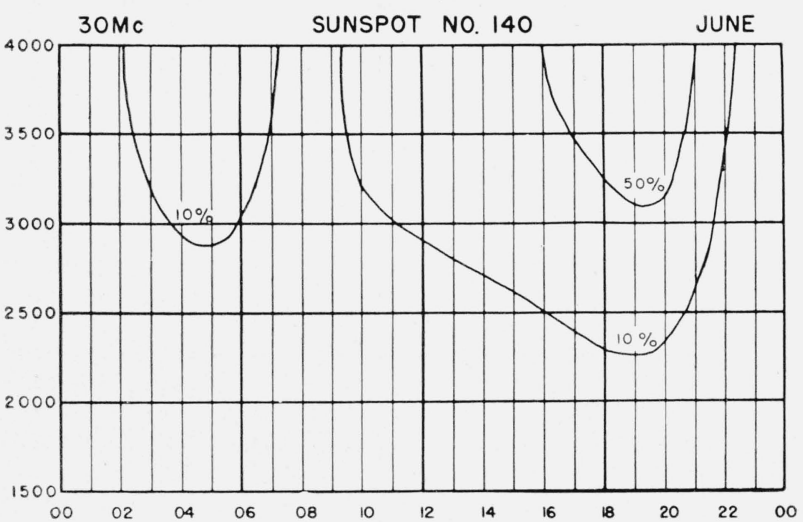

FIG. 45

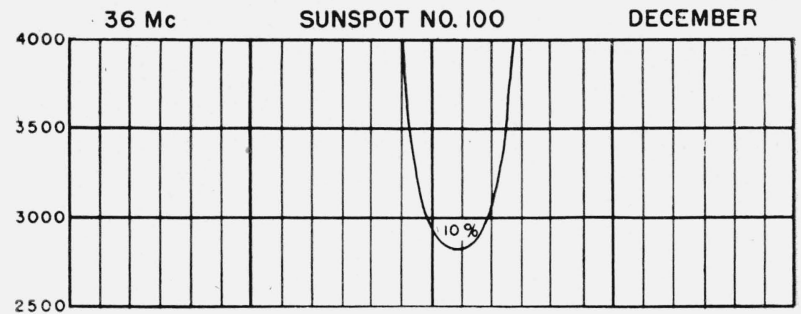

FIG. 46

SUNSPOT NO. 120 DECEMBER

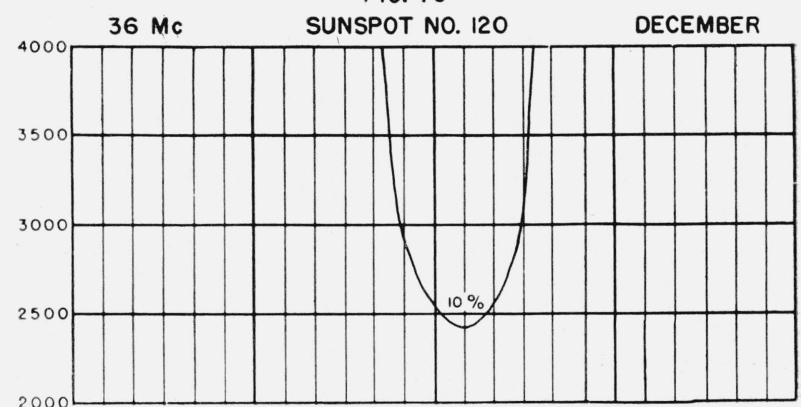

FIG. 47

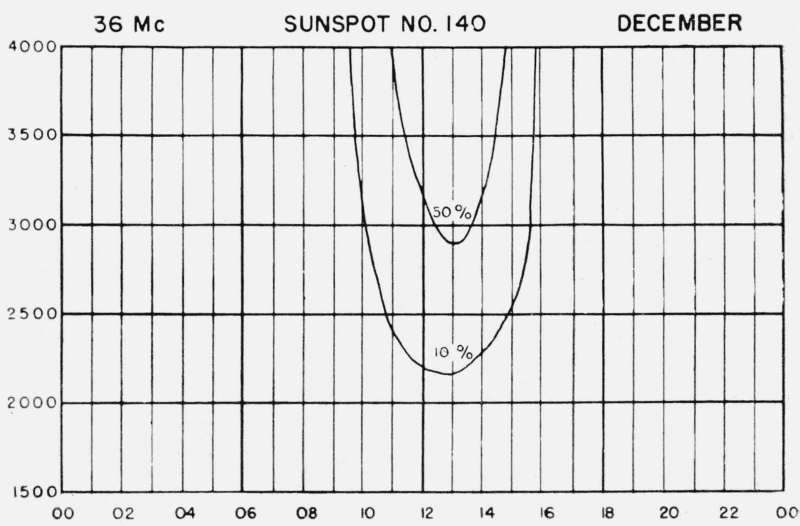

POINT OF THE PATH

Figures 42 to 47. Predicted skip distance for F2-layer reflection at $60^{\circ} \mathrm{N}$. latitude, I-zone.

Fig. 48

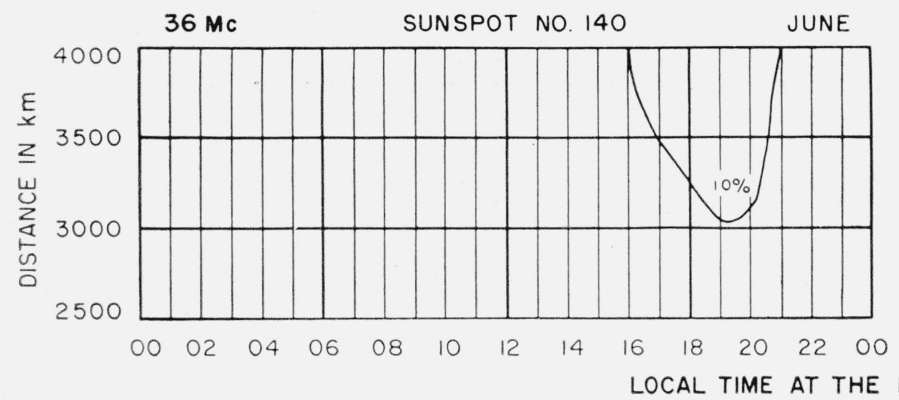

Fig. 49

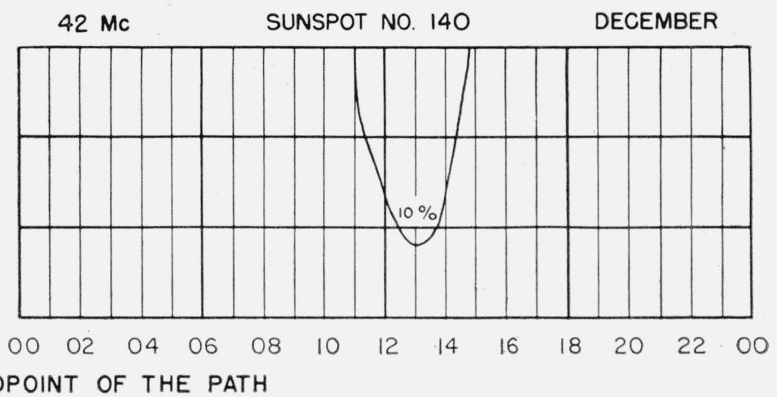

Figures 48 and 49. Predicted skip distance for F2-layer reflection at $60^{\circ} \mathrm{N}$. latitude, I-zone. 


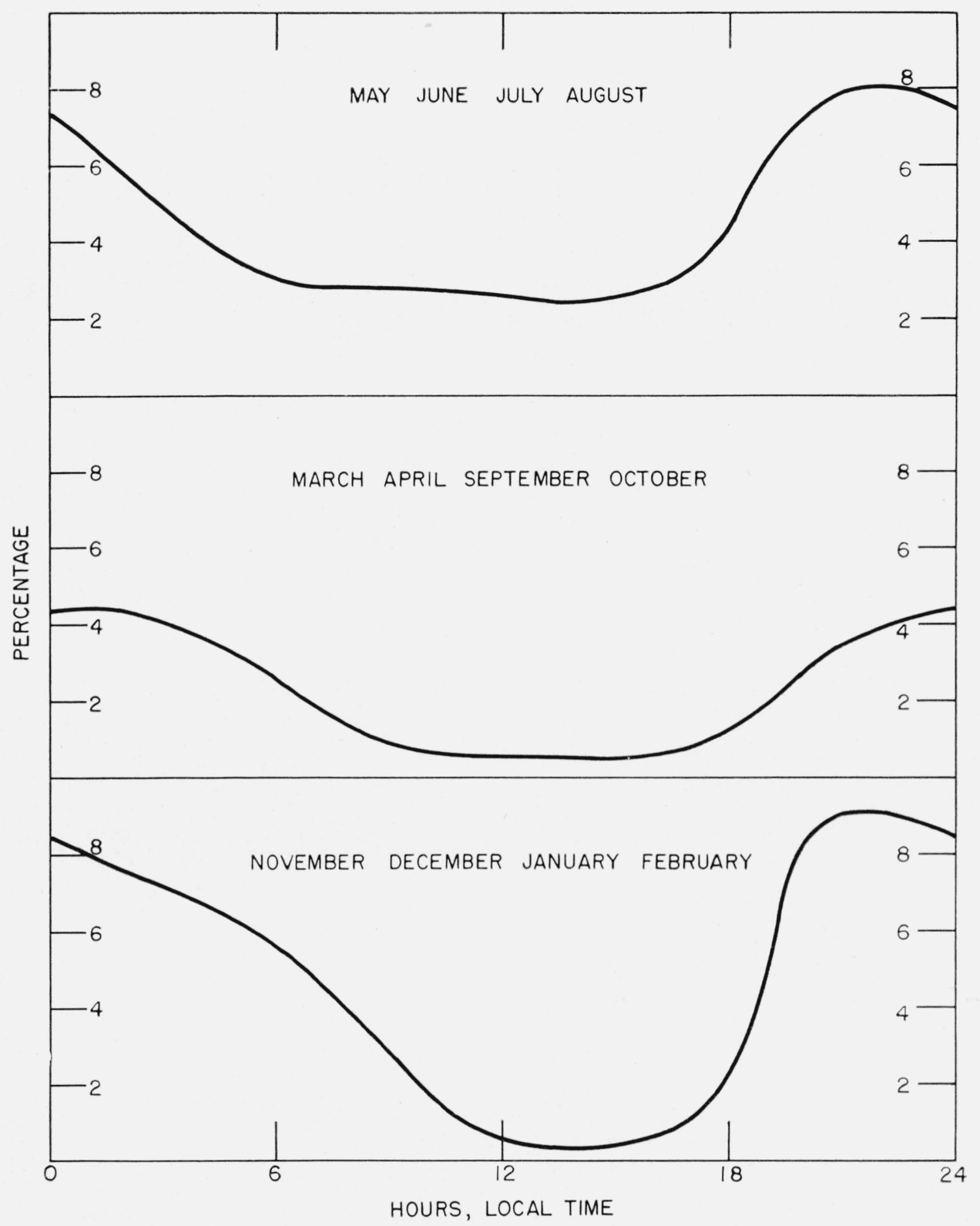

Figure 50. Diurnal variation in percentage of time of occurrence of sporadic E reflections in excess of $\gamma$ Mc, Anchorage, Alaska May 1949-A pril 1953.

Washington, July 1953. 